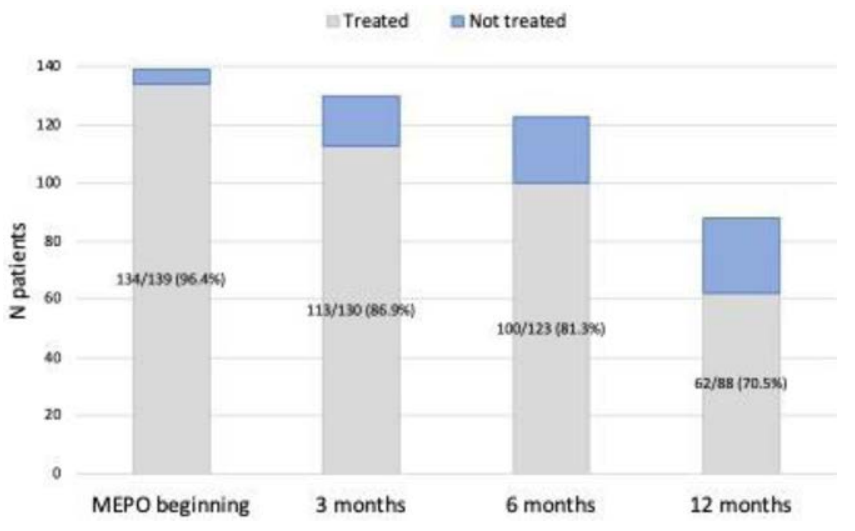

Figure 2. Steroid treatment

Conclusion: MEPO effectively controlled systemic and respiratory EGPA symptoms in a large European cohort, with no major safety concerns.

References:

[1] Wechsler et al. MEPO or Placebo for Eosinophilic Granulomatosis with Polyangiitis. NEJM. 2017

Disclosure of Interests: Alessandra Bettiol: None declared, Maria Letizia Urban: None declared, Federico Alberici: None declared, Carlo Agostini: None declared, Chiara Baldini: None declared, Enrica Bozzolo: None declared, Paolo Cameli: None declared, Nunzio Crimi: None declared, Stefano Del Giacco: None declared, Allyson Egan: None declared, Georgina EspigolFrigole Consultant of: Roche and Janssen, Mara Felicetti: None declared, Marco Folci: None declared, Paolo Fraticelli: None declared, Marcello Govoni: None declared, Anna Kernder Grant/research support from: Grant/research support from: GlaxoSmithKline and UCB Pharma for performing the LuLastudy., Carlo Lombardi: None declared, Giuseppe Lopalco: None declared, Claudio Lunardi: None declared, Aladdin J Mohammad Speakers bureau: lecture fees from Roche and Elli Lilly Sweden, PI (GiACTA study), Frank Moosig: None declared, Simone Negrini: None declared, Thomas Neumann: None declared, Pavel Novikov Grant/research support from: This work was supported by the 5-100 Project, Sechenov University, Moscow, Giuseppe Paolazzi: None declared, paola parronchi: None declared, Luca Quartuccio Consultant of: Abbvie, Bristol, Speakers bureau: Abbvie, Pfizer, Vito Racanelli: None declared, Carlo Salvarani: None declared, Maxime Samson: None declared, Jan Schroeder: None declared, Savino Sciascia: None declared, Renato A. Sinico: None declared, Benjamin Terrier: None declared, Paola Toniati: None declared, Domenico Prisco: None declared, Augusto Vaglio: None declared, Giacomo Emmi: None declared

DOI: 10.1136/annrheumdis-2020-eular.5544

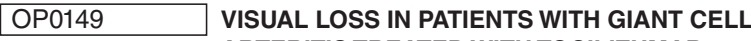 ARTERITIS TREATED WITH TOCILIZUMAB}

J. Amsler ${ }^{1}$, I. Kysela ${ }^{1}$, L. Christ ${ }^{1}$, C. Tappeiner ${ }^{2}$, L. Seitz ${ }^{1}$, G. Scholz ${ }^{1}$, F. Kollert ${ }^{1}$, S. Reichenbach ${ }^{1}$, P. Villiger ${ }^{1} .{ }^{1}$ Bern, Department of Rheumatology, Immunology and Allergology, Bern, Switzerland; ${ }^{2}$ Bern, Department of Opthalmology, Bern, Switzerland

Background: Whether Tocilizumab (TCZ) may prevent vision loss in Giant Cell Arteritis (GCA) to the same extent as glucocorticoids remains a key and unanswered question. A patient cohort observed over up to 8 years addresses this issue.

Objectives: To investigate the frequency of vision loss/visual impariment in a GCA cohort treated with TCZ.

Methods: In this observational monocentric study, the courses of 192 patients with GCA treated with TCZ between 01.01.2011 and 31.12.2018 were analyzed. Data were extracted from medical records and collected in a Clinical Trial Unit (CTU) - based registry. Demographic, clinical and laboratory data were analyzed.

Results: 192 patients with GCA were treated with TCZ; 121 (63\%) were female, $112(58 \%)$ fulfilled 1990 American College of Rheumatology (ACR) criteria, all others had large vessel vasculitis based on magnetic resonance-angiography (MRA). The cumulative duration of TCZ treatment was 3467 months; the median treatment duration was $13.8(8.5 ; 22.8)$ months. At baseline, visual impairment was present in $71(37 \%)$ and vision loss in 21 (7.8\%) patients. Visual loss was associated with higher age $(74(70 ; 82)$ vs. $70(63 ; 76)$ years; $p=0.029)$, lower C-reactive protein at baseline $(14.0(3.5 ; 42.0)$ vs. $54.5(21.0 ; 101.0) \mathrm{mg} / \mathrm{l}$; $p<0.001)$, cranial symptoms $(p<0.0001)$, jaw claudication $(p=0.030)$ and negative MRA of the aorta $(p=0.020)$. Over the observed time span only one patient taking part in a clinical trial developed vision loss. In total $4(2 \%)$ patients with vision impairment showed deterioration and 61 (32\%) improvement.

Conclusion: Collectively, our data suggest that TCZ is able to prevent visual loss and may have a favorable effect on visual impairment.

Disclosure of Interests: Jennifer Amsler: None declared, Iveta Kysela: None declared, Lisa Christ Consultant of: BMS, Christoph Tappeiner: None declared, Luca Seitz: None declared, Godehard Scholz: None declared, Florian Kollert Employee of: Novartis, Stephan Reichenbach: None declared, Peter Villiger Consultant of: MSD, Abbvie, Roche, Pfizer, Sanofi, Speakers bureau: Roche, MSD Pfizer

DOI: 10.1136/annrheumdis-2020-eular.6068

\section{OP0150 WHAT IS THE ROLE OF TEMPORAL ARTERY BIOPSY IN GIANT CELL ARTERITIS FAST-TRACK PATHWAYS WHEN TEMPORAL ARTERY ULTRASOUND IS NEGATIVE?}

A. Sachdev ${ }^{1}, \underline{\text { S. Dubey }}{ }^{2}$, C. Tiivas ${ }^{3}$, M. George ${ }^{3}$, P. Mehta ${ }^{3} .{ }^{1}$ Russells Hall Hospital, Dudley, United Kingdom; ${ }^{2}$ Oxford University Hospitals NHS Foundation Trust, Oxford, United Kingdom; ${ }^{3}$ University Hospital Coventry and Warwickshire NHS Trust, Coventry, United Kingdom

Background: A number of centres are now running fast track pathways for diagnosis and management of Giant cell arteritis with ultrasound as the first port of call for diagnosis ${ }^{1}$. Temporal artery biopsies (TABs) have become the second line of investigation, and it is unclear how useful TAB is in this setting.

Objectives: This study looked at accuracy of Temporal artery biopsy (TAB) in patients with suspected Giant Cell arteritis (GCA) with negative/inconclusive ultrasound $(\mathrm{U} / \mathrm{S})$ and how duration of treatment on steroids prior to these investigations and arterial specimen size affected it.

Methods: Prospective study of all patients with suspected GCA referred for TAB when U/S was negative or inconclusive, as part of the local fast-track pathway (Coventry). Database included clinical findings, serological work up, U/S and TAB results and treatment. Sensitivity and specificity of U/S and TAB was calculated and compared based on duration of treatment with steroids.

Results: One hundred and nine patients were referred for TAB via Coventry fast-track-pathway. The sensitivity of U/S in this cohort of patients was $9.08 \%$ and specificity was $93.33 \%$. After 3 days of steroid this was $0 \%$ and $100 \%$ respectively. For TAB when done within 10 days of starting steroids, this was $65 \%$ and $87.5 \%$ respectively. After 20 days of steroids this was $0 \%$ and $100 \%$. The sensitivity and specificity was $20 \%$ and $85 \%$ when arterial specimen size was $11-15 \mathrm{~mm}$ and $47 \%$ and $100 \%$ when specimen size was $16 \mathrm{~mm}$ or more. Sensitivity and specificity of U/S of 644 suspected GCA patients was $48 \%$ and $98 \%$.

Conclusion: Our study demonstrates that TAB plays a relevant role in GCA fasttrack-pathways, when $\mathrm{U} / \mathrm{S}$ is negative/inconclusive. TAB was more sensitive than $\mathrm{U} / \mathrm{S}$ in this cohort of patients, but overall sensitivity of U/S was higher when calculated for all patients suspected with GCA. Both remain useful tests if performed early. TAB specimen size should ideally be $16 \mathrm{~mm}$ or more and done within 10 days of starting steroids.

References:

[1] Jonathan Pinnell, Carl Tiivas, Kaushik Chaudhuri, Purnima Mehta, Shirish Dubey, 038 The diagnostic performance of ultrasound Doppler in a fasttrack pathway for giant cell arteritis, Rheumatology, Volume 58, Issue Supplement_3, April 2019, kez105.036, https://doi.org/10.1093/rheumatology/ kez105.036

Disclosure of Interests: None declared

DOI: 10.1136/annrheumdis-2020-eular.6534

\section{OP0151-PARE WORK IMPACTS EXPERIENCED BY YOUNGER PEOPLE WITH ARTHRITIS: A SYSTEMATIC REVIEW}

D. Berkovic ${ }^{1}$, C. Parker ${ }^{1}$, D. Ayton ${ }^{1}$, A. M. Briggs ${ }^{2}$, I. Ackerman ${ }^{1} .{ }^{1}$ Monash University, Melbourne, Australia; ${ }^{2}$ Curtin University, Melbourne, Australia

Background: On a global scale, it is estimated that adults in their peak income-earning years are disproportionately impacted by arthritis (1). Younger adults with arthritis are less likely to be employed and are more likely to face productivity challenges at work when compared to healthy similar-aged peers (2). The work-related impacts of arthritis on younger adults remain largely unexplored and are rarely considered in routine clinical care for arthritis.

Objectives: To systematically identify, appraise and synthesise the available evidence on work impacts experienced by individuals aged 16-50 years with arthritis. 